\title{
Basic principle for the solution of the building evacuation problem
}

\author{
Salvador Casadesús Pursals, Federico Garriga Garzón \\ Universitat Politècnica de Catalunya (SP AIN) \\ salvador.casadesus@upc.edu;federico.garriga@upc.edu
}

Received April 2009

Accepted July 2009

\begin{abstract}
Nowadays, there exist different offers to find the solution of the building evacuation problem. As we analyze in the state of the art, this problem can be studied from different perspectives and even as a problem of optimization considering different objectives. We can wonder on which is the most suitable formulation and the response can be as confusing as saying that it depends on our aims. The more important things to study the ideal building evacuation, understood as the distribution of the occupants towards the exits that achieves the minimal evacuation time, are the valid principles for any formulation of the problem. One of them appears in the present work. To expose the principle, we use graphical procedures that are applied to the optimization of the enclosure evacuation. In the exposed procedure, speeds and constant flows of traffic are considered to model the movement of the persons. Ways and possible delays in the beginning of the bulging evacuation are studied.
\end{abstract}

Keywords: building evacuation, evacuation optimization, optimal building evacuation

\section{Introduction}

A lot of dangerous situations can occur in buildings: Fires, gas leaks, toxic clouds in immediate zones, catastrophic atmospheric phenomena, bombs threaten, collective uncontrolled reactions and other circumstances in which the occupants look for the 
exits desperately. In front of any contingency of considerable magnitude, the occupants should have the possibility of leaving the building rapidly and safely.

The occupants' evacuation is one of the most important concepts of the buildings safety. In principle, the buildings are safe if they are constructed according to certain procedures, dictated by procedure and regulations of construction and safety against fires. In them, the dimensions of the evacuation elements are established: minimal widths and maximum length of the ways. Nevertheless, in the relation between the occupants and the enclosure, a lot of questions remain without answer: Which is the necessary time for the building evacuation?, which is the distribution towards every exit that obtains a minimal evacuation time?, what happen if the occupants' totality try to use the same exit?, which is the effect of increase the width of an emergency exit?.

In some buildings it is possible to carry out shams of evacuation: educational centers, certain industrial centers and other cases, but in the majority it is not possible. They are not viable, for example, in commercial or recreative centers occupied by hundreds of persons. In these cases, to solve some of the raised aspects and to have certain knowledge of the problem magnitude and their possible solutions it is necessary to use quantitative technologies of analysis.

\section{The problem of the building evacuation: State of the art}

The study of the problem begins with the analysis of cases where we try to identify the determinant factors of the development of big sinister. The above mentioned situations, in the majority of cases, are related to fires. From this perspective, regulations and technical prescriptions applicable to the design and to the utilization of the buildings have been written. From the multitude of studied cases, they deserve special attention the analysis of the fire of the theatre of Edinburgh in 1911, because it was a pioneering work in the study of the human locomotion, and the investigations of the occupants performance and in general the evolution of the events instants after materializing the attempts of the World Trade Center of New York of September 11, 2001. These researches include several disciplines. The investigative effort is very important, because it goes far beyond of the traditional study of cases. 
A deeper study of the building evacuation problem is tied to the evaluation of quantitative aspects. An essential element for this study is the knowledge of the movement of the persons. The first document of reference is the report of the London Transport Board (1958), more rigorous works are developed in the eighties (Fruins, 1971-1987) in the USA and Pauls (1980, 1984, 1996) in Canada. In the same time, the researches developed previous years in the USSR by Predtechenskii and Milinskii (1969-1978) are divulged. The models of Fruins and Pauls are synthesized in diverse manuals of the Society of Fire Protection Engineering (Nelson, 1996). In the line of the models developed in the USSR, reference of Kholshenikov (2006) publications exists.

The first publications of mathematical models which try to estimate the time of building evacuation owe to Togawa (1955) and to Melinnek and Booth (1975). These constitute a fundamental step in the solution of the problem, but operative research contributes the effective solution. From this discipline, the first formulation of the problem of the building evacuation owes to Francis $(1979,1981)$ using the algorithm of Brown (1979) for the resolution. The first author who use flow nets was Berlin (1980). Francis with Chalment and Saunders (1982) in a later publication study the building evacuation by flow nets, and later, Francis and Kisko realize the program EVACNET $(1984,1985)$, one application developed in FORTRAN 77 that allows to determine evacuation times as well as the ideal distribution of the occupants towards the exits.

In the same line of deterministic models and flow nets, years later Choi, Hamacher and Tufekcy (1988) consider the problem as a situation of flow nets with capacity restrictions and arches with changeable capacity, providing greedy algorithms for the solution of certain structures. In the nineties Hope and Tardos (1994, 1995) contribute interesting solutions by polynomial algorithms based on the works of Minieka (1973) and Megiddo (1974, 1979). At the beginning of the current decade the works developed by Tjandra and Hamacher $(2003,2004)$, are really significant. Their contributions are very valuable to solve the problem by flow nets. Another approach to the problem is the realized (Kostreva, 1991; Getachew, 1992, 2000; Wiecek, 1992, 1993), who formulate the building evacuation as a multiobjective problem. Continuing this line of research we find Lo and Huang (2000, 2006, 2008). Other more recent solutions with interesting contributions are the formulated (Gupta \& Yadav, 2004), as well as the heuristic solution for changeable flow nets (Lu, Huanng \& Shekhar, 2003, 2003, 2005). 
The problem also has been studied from a stochastic perspective, with models that contribute with major realism but its resolution is more laborious. The most emphasized authors in this line (Smith, 1984, 1985, 1996; Lovas, 1992, 1995, 1998). In the first formulations, they use tails nets whose solution is based on the algorithms of Resier and Lavenberg (1978, 1980), later they contribute proper solutions and in some cases they solve the complex tails nets by simulation.

In the last years, the studies that have proliferated more are the simulations. As a pioneer document, it is necessary to mention the work realized Weinroth (1989), as well as numerous programs: EXITT, EVACSIM, EXIT-89, TIMTEX, STEPS, CRISP, ASERI, PEDGO, PEDROUTE, and WAY OUT between others. Of all the known applications, possibly the most spread correspond to the program SI-MULEX (Thomson, 1995) and EXODUS (Galea, 1993, 1994, 2001), both developed in the United Kingdom and available commercially.

\section{The problem of the enclosure evacuation}

With the term "enclosure" we indicate a zone of a building occupied by a certain number of persons from which there exists at least a way of evacuation that leads to a safe zone. The problem is relevant when the number of occupants is considerable and several exits exist.

We represent an enclosure in the figure (Figure 1), with $k$ occupants uniformly distributed, and with $\mathrm{n}$ possible exits, placed in such a way that there does not exist interference in the movement of the occupants who go to each of them.

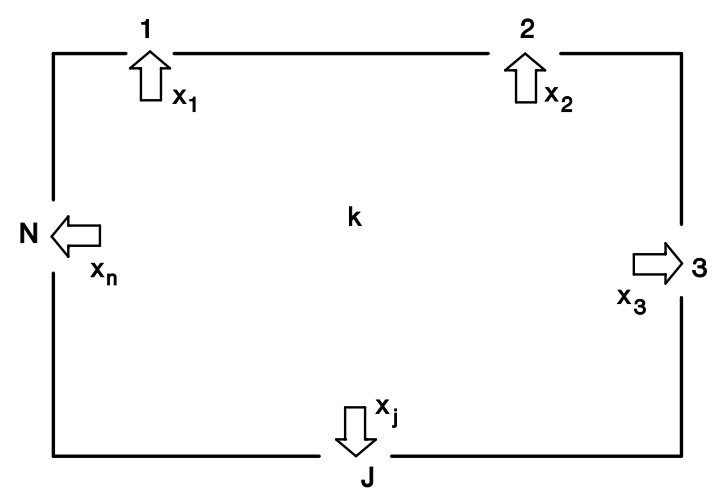

Figure 1. "Example of enclosure". 
For each of the exits, $j=1,2, \ldots, n$, it is possible to suppose a certain flow $f_{j}$ that allows to know the evacuation function $t_{j}\left(x_{j}\right) \quad 0 \leq x_{j} \leq k$. This function, strictly increasing $t_{j}\left(x_{j}\right) \geq 0 \forall x_{j} y t_{j}\left(x_{j}\right)=0$ si $x_{j}=0$, indicates the time that $x_{j}$ persons will need to go out of the enclosure if they use the $j$ exit

The problem consists in finding the number of people $x j$ that must use each exit to minimize the total time of evacuation. If $n$ independent exits exist, there will be $n$ ways or different routes from evacuation. The evacuation time of the enclosure will be the duration of the longest way, defined by the instant in which the last occupant reaches the exterior.

Calling $z$ to the evacuation time, we obtain the target function (1), which holds the restrictions defined in (2) and (3).

$$
\begin{aligned}
& \operatorname{Min}(\mathrm{z})=\operatorname{Max}\left[\mathrm{t}_{1}\left(\mathrm{x}_{1}\right), \ldots \mathrm{t}_{\mathrm{n}}\left(\mathrm{x}_{\mathrm{n}}\right)\right] \\
& \mathrm{x}_{1}+\mathrm{x}_{2}+\ldots+\mathrm{x}_{\mathrm{n}}=\mathrm{k} \\
& \mathrm{x}_{1} \geq 0, \mathrm{x}_{2} \geq 0, \ldots, \mathrm{x}_{\mathrm{n}} \geq 0
\end{aligned}
$$

If $k$ persons must go out of the enclosure, necessarily there must be fulfilled that the number of persons evacuated among all the routes is equal to $k$, the total number of occupants. It is not possible that the number of persons who use a certain route is a negative number and in the problem formulation $\mathrm{xj}$ has not been established as an entire value when it necessarily must be entire.

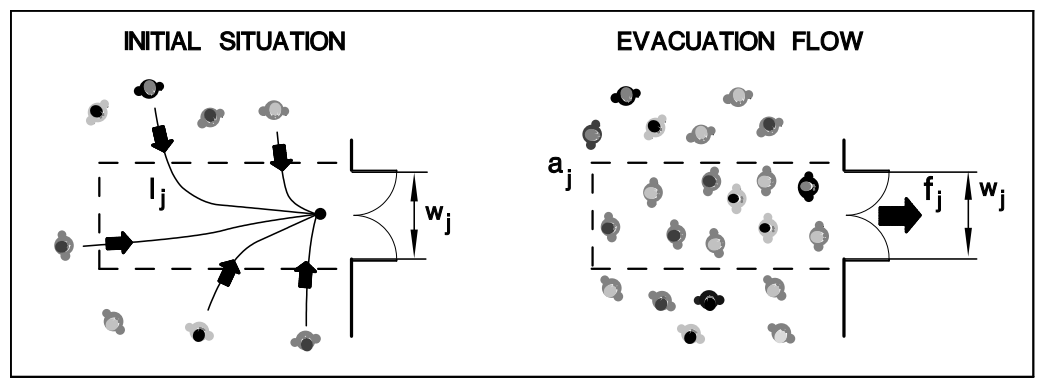

Figure 2. "Modeling the incorporations to the exits".

The evacuation function $t_{j}\left(x_{j}\right)$ is obtained from the persons' movement model proposed by J. Fruins (1987). The process of flow formation can be analyzed in the figure 2 . There, when the alarm sign is produced, the occupants in any place go to 
the $j$ exit. This exit registers a specific flow $f_{e j}$ whose magnitude is supposed constant during all the evacuation. From this, we obtain the flow $\mathrm{f}_{\mathrm{j}}$ :

$$
\mathrm{f}_{\mathrm{j}}=\mathrm{f}_{\mathrm{e}, \mathrm{j}} \times \mathrm{w}_{\mathrm{j}}
$$

Being $w_{j}$ the minimal width of the $j$ exit. Supposing that all the occupants initiate the evacuation in the same instant of time, the evacuation function $t_{j}\left(x_{j}\right)$ has the following expression:

$$
t_{j}\left(x_{j}\right)=\frac{x_{j}}{f_{j}}
$$

In case of delays at the beginning of the evacuation which cause that the occupants carry out a way $\mathrm{l}_{\mathrm{j}}$ to the exit, the evacuation function include the terms $t_{0, j}$ y $t_{1, j}$ :

$$
t_{j}\left(x_{j}\right)=t_{0, j}+t_{1, j}+\frac{x_{j}}{f_{j}}
$$

where $t_{0, j}$ indicates the time that use the occupants of the $j$ exit who delay the beginning of the evacuation. This is an estimated value that depends on diverse factors: type of building, characteristics of the occupants, communication systems and signposting. In the other hand, $t_{1, j}$ indicates the time that the occupants of the $\mathrm{j}$ route need to reach the exit. Supposing constant speed during the interval of evacuation time, and $\mathrm{I}_{\mathrm{j}}$ the ways, we obtain:

$$
t_{1, j}=\frac{l_{j}}{v_{l}}
$$

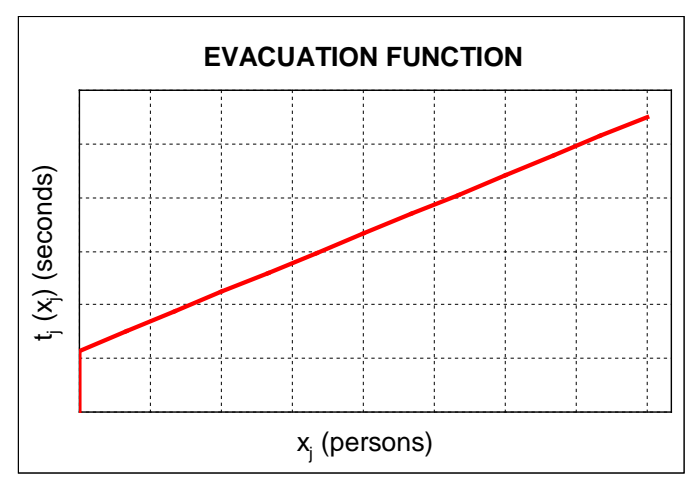

Figure 3. "Evacuation function". 
The graphical representation of the evacuation function is showed in the figure 3. There, the ordinate in the origin represents the time that the occupants use to reach the exit, which is the addition of the evacuation delay time and the time of the way.

\section{Solution of the problem}

To solve the problem from the evacuation functions $t_{j}\left(x_{j}\right)$ of each exits, it is necessary to find their inverse functions called $p_{j}(z)$, which show the number of persons who can go out of the enclosure using the exit $j$ in a $z$ time.

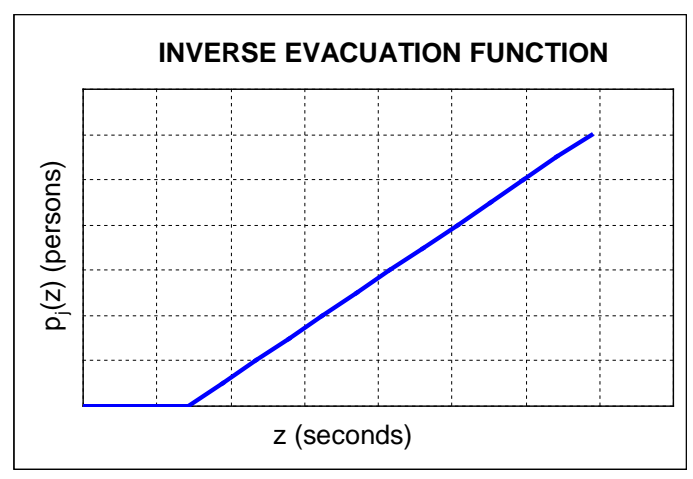

Figure 4. "Inverse evacuation function".

the analytical solution presents some difficulties as: to determine the inverse evacuation functions $p_{j}(z)$, to evaluate the total evacuation function $P(z)$, to solve the equation for $k$ occupants and finally to solve the assignment of every exit. The graphical procedure formulated by R. L. Francis (1979) to solve the problem when the evacuation functions are monotonous, turns out to be relatively simple. This procedure has been generalized considering ways and delays at the beginning of the evacuation, and it has been transformed to use calculation tools, turning out to be the following procedure:

- To determine for every exit $j$ the evacuation function $t_{j}\left(x_{j}\right)$.

- From the evacuation function $t_{j}\left(x_{j}\right)$, find the inverse evacuation function $p_{j}(z)$ for each of the exits. It is necessary to represent the evacuation function $t_{j}\left(x_{j}\right)$ placing the times of evacuation $z$ in the abscissas axis and the number of persons $p_{j}(z)$ in the ordinate axis. 
- To carry out the graphical representation of the total evacuation function $\mathrm{P}_{\mathrm{T}}(\mathrm{z})$ that indicates the total number of persons who can go out of the enclosure in a $z$ time. If the exits are independent, it is enough to add the corresponding values of each one, represented by the functions $p_{j}(z)$.

- To place the occupants number of the enclosure $k$ in the ordinate axis. To plan from this point a horizontal line up to the intersection with $\mathrm{P}_{\mathrm{T}}(\mathrm{z})$. Later, from the point of intersection draw a vertical line. In the abscissas axis one can read the necessary time for the evacuation of $k$ occupants, which is the minimal time of evacuation $z^{*}$.

- From the intersections of the vertical line with the functions $p_{j}(z)$ of each exit, horizontal lines are planned. That allows to establish in the ordinate axis the assignment $p_{j}\left(z^{*}\right)$ of each exit $j$.

$$
\mathrm{p}_{\mathrm{j}}\left(\mathrm{z}^{*}\right)=\mathrm{x}_{\mathrm{j}}{ }^{*}
$$

- Finally one must check that all the occupants have been evacuated:

$$
\mathrm{x}_{1} *+\ldots .+\mathrm{x}_{\mathrm{n}} *=\mathrm{p}_{1}\left(\mathrm{z}^{*}\right)+\ldots \ldots+\mathrm{p}_{\mathrm{n}} *\left(\mathrm{z}^{*}\right)=\mathrm{k}
$$

The precision of the results will depend on the size of the graph as well as on the visual keenness of the readings.

\section{Study of an enclosure evacuation}

We suppose an rectangular enclosure of $60 \times 40 \mathrm{~m}$. with an insertion in the low face of $16.5 \times 18 \mathrm{~m}$., which turns out to be an approximately a total surface of $2100 \mathrm{~m}^{2}$. It has 3 independent exits and ways, with surface $a_{j}\left(\mathrm{~m}^{2}\right)$ which go to each of the exits, with a minimal width $w_{j}(m)$ and an evacuation way of $I_{j}(m)$. In the enclosure there are 610 persons distributed uniformly. The characteristics of the enclosure are summarized in the following table:

\begin{tabular}{|c|c|c|c|}
\hline $\mathbf{j}$ & $\mathbf{w}_{\mathbf{j}}$ & $\mathbf{l}_{\mathbf{j}}$ & $\mathbf{a}_{\mathbf{j}}$ \\
\hline 1 & 2.0 & 35 & 90 \\
\hline 2 & 1.6 & 25 & 75 \\
\hline 3 & 1.2 & 20 & 70 \\
\hline
\end{tabular}

Table 1. "Characteristics of the enclosure". 


\subsection{CASE 1: Delays and evacuation ways are not considered}

It is supposed that delays do not take place at the beginning of the evacuation. In the moment when the alarm rings, $x_{j}$ occupants go automatically to the corridor of exit $j$, being constant the traffic flows and in one direction. Evacuation ways are not considered. Continuing the process detailed previously, representing graphically in the figure 5 .

- To determine for every exit $\mathrm{j}$ the function of evacuation $t_{j}\left(x_{j}\right)$.

- From the evacuation function $t_{j}\left(x_{j}\right)$, find the inverse evacuation function $p_{j}(z)$ for each of the exits. To obtain this, the evacuation function should be represented $t_{j}\left(x_{j}\right)$ placing the evacuation times $z$ in the abscissas axis and the number of persons $p_{j}(z)$ in the ordinate axis.

$$
p_{1}(z)=2.17 z \quad p_{2}(z)=1.73 z \quad p_{3}(z)=1.30 z \quad z \geq 0
$$

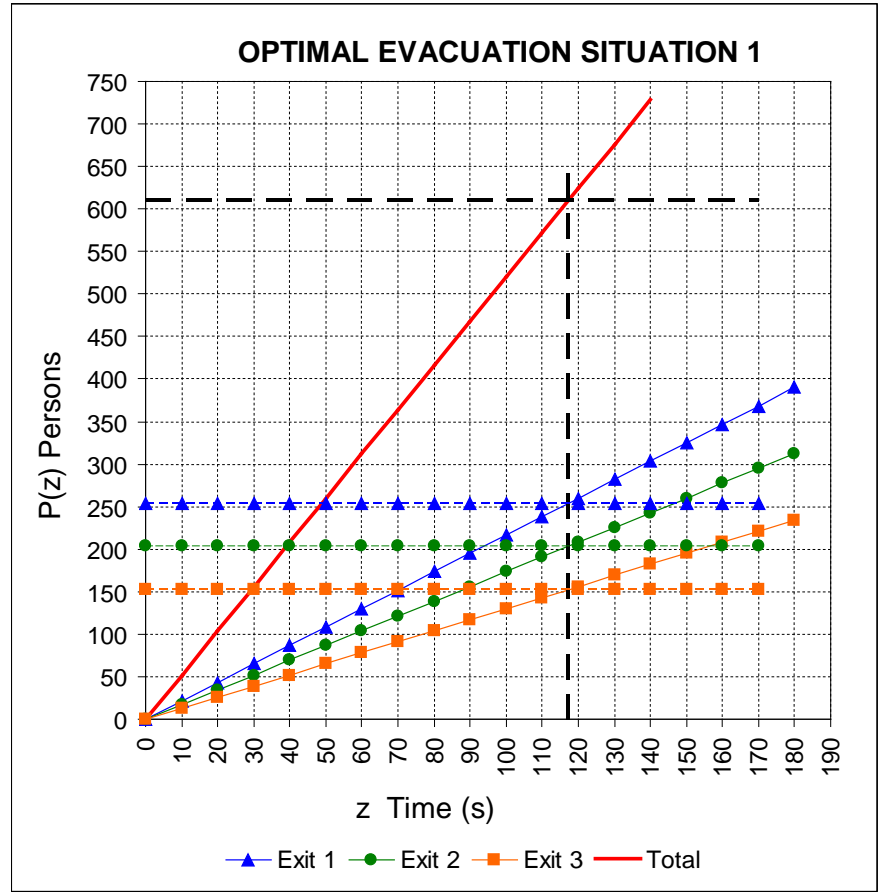

Figure 5. "Solution case 1".

- Carry out the graphical representation of the total evacuation function $\mathrm{P}_{\mathrm{T}}(z)$ that indicates the total number of persons who can go out in a $z$ time. If the exits are independent, it is enough to add the corresponding values of each one of them represented by the functions $p_{j}(z)$. 


$$
P_{T}(z)=p_{1}(z)+p_{2}(z)+p_{3}(z)=5.20 z \quad z \geq 0
$$

- To place the occupants' number of the enclosure $k=610$ in the ordinate axis. To plan from this point a horizontal line up to the intersection with $\mathrm{P}_{\mathrm{T}}(\mathrm{z})$, later, from the point of intersection draw a vertical line. In the abscissas axis, one can read the necessary evacuation time of 610 occupants, which is the minimal time of evacuation $z^{*}=118$ seconds.

- From the intersections of the vertical line with the functions $p_{j}(z)$ of each exit, plan horizontal lines, which allow to establish in the ordinate axis the assignment $\mathrm{p}_{\mathrm{j}}\left(\mathrm{z}^{*}\right)$ of each exit $\mathrm{j}$.

$$
\mathrm{p}_{1}(\mathrm{z})=254 \text { persons } \quad \mathrm{p}_{2}(\mathrm{z})=204 \text { persons } \quad \mathrm{p}_{3}(\mathrm{z})=152 \text { persons }
$$

- Finally one must check that all occupants have been evacuated:

$$
\mathrm{p}_{1}(\mathrm{z})+\mathrm{p}_{2}(\mathrm{z})+\mathrm{p}_{3}(\mathrm{z})=254+204+152=610 \text { persons }
$$

The solution of the problem can be obtained for any number of occupants, between 0 and 750 , approximately.

\subsection{CASE 2: Ways of evacuation are considered}

In this case delays at the beginning of the evacuation are not admitted, but ways $I_{j}$, which the occupants of the enclosure must carry out to come up to the exit are considered. The traffic speed and the flow are constant during all the evacuation. Of the expression (7) we obtain the evacuation function of each exit:

$$
t_{1}\left(x_{1}\right)=52.5+\frac{1}{2.17} x_{1} \quad t_{2}\left(x_{2}\right)=37.5+\frac{1}{1.73} x_{2} \quad t_{3}\left(x_{3}\right)=30+\frac{1}{1.30} x_{3}
$$

From the evacuation function $t_{j}\left(x_{j}\right)$, we represent graphically the inverse evacuation function $p_{j}(z)$ of each exit and we find the total evacuation function $\mathrm{P}_{\mathrm{T}}(z)$. Doing the same process of the previous case, we obtain the solution of the figure 6 .

The evacuation time is $z^{*}=159$ seconds and the assignment towards each exit:

$$
\mathrm{p}_{1}(\mathrm{z})=230 \text { persons } \quad \mathrm{p}_{2}(\mathrm{z})=210 \text { persons } \quad \mathrm{p}_{3}(\mathrm{z})=170 \text { persons }
$$

If we add all these values, we obtain the totality of the occupants of the enclosure.

$$
\mathrm{p}_{1}(\mathrm{z})+\mathrm{p}_{2}(\mathrm{z})+\mathrm{p}_{3}(\mathrm{z})=230+210+170=610 \text { persons }
$$




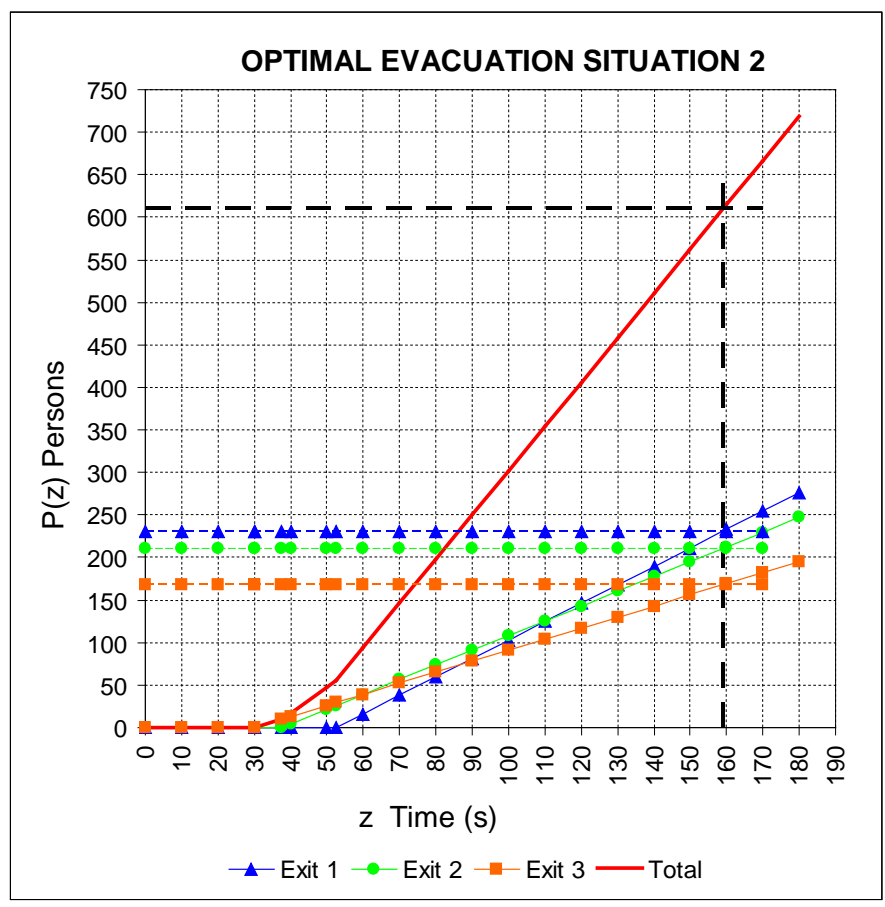

Figure 6. "Solution case 2".

\subsection{CASE 3: Evacuation ways and delays are considered}

In this case besides the evacuation ways, we consider a delay of 25 seconds in the exit 1 . This time passes between the instant in which the sign of alarm takes place and the moment in which the occupants of the enclosure initiate the evacuation towards this exit. In this case, the evacuation function of the exit 1 has the following expression:

$$
t_{1}\left(x_{1}\right)=77.5+\frac{1}{2.17} x_{1}
$$

The remaining evacuation functions take the same value that in the previous case. Proceeding equally like the previous cases, we obtain the graph of the figure 7 .

The optimal evacuation time $z^{*}=170$ seconds and the ideal distribution respect the evacuation condition of 610 occupants:

$$
\mathrm{p}_{1}(\mathrm{z})=200 \text { persons } \quad \mathrm{p}_{2}(\mathrm{z})=230 \text { persons } \quad \mathrm{p}_{3}(\mathrm{z})=180 \text { persons }
$$




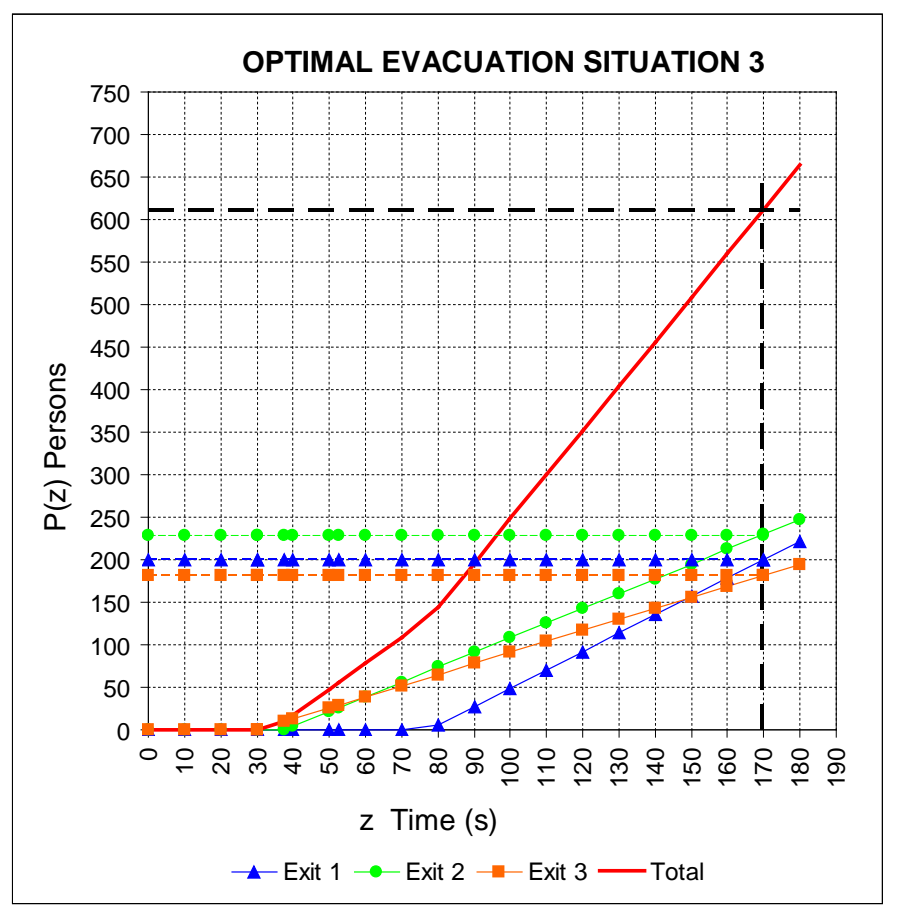

Figure 7. "Solution case 3".

\section{Conclusions}

In the present work, we have obtained the ideal distribution of the occupants towards the exits, with the minimal evacuation time in the three cases. To achieve the ideal enclosure evacuation, in the conditions of the problem formulation, without capacity restrictions in the destinations and independent ways, there exists a basic principle: The evacuation times registered in each of the exits must be identical.

This principle can be reasoned easily, since the time of evacuation is determined by the instant in which the last occupant leaves the building. If the number of occupants who go to an exit increase, it prove a major evacuation time. Necessarily, in the rest of exits the assignment turns out to be minor and in consequence, they have a minor the time of evacuation. Nevertheless the time of evacuation of the building is determined by the time of evacuation of the first exit, which has been increased. Equally, if we assign fewer occupants to one exit, in at least one of other exits the assignment should be major. That would increase the evacuation time and this time would be the one that determine the evacuation time of the enclosure. These changes do not drive to an ideal solution. We observe that 
to manage the minimal evacuation time of an enclosure, if the outflows are independent, it is necessary to achieve the distribution that produces identical times of evacuation.

With more or less difficulty, almost always it is possible to obtain the evacuation function of an exit of analytical form, estimating the number of persons who can go out of the enclosure. Repeating the process for all the exits of the enclosure, the rest of evacuation functions will be obtained and finally it will be possible to determine the condition of balance that leads to the ideal problem solution. If the problem is formulated by other procedures as tails nets or simulation, the approach to determine the optimal solution of the problem would be exactly the same one. With the mentioned procedures, the evacuation functions would be obtained, and the optimal solution would be calculated from the principle of balance: the minimal time of evacuation and the distribution of the occupants towards the exits that leads the same one.

Another distinguished characteristic from the graphical procedure is that makes possible to determine which would be the results of the problem with changes in the number of occupants, the width of the exits, the ways of evacuation, or response variations to the alarm sign. It is a very useful tool for the persons who design and manage the buildings safety.

\section{Appendix data sources for modeling evacuations}

Fruins (1971 - 1987) models of occupation and movement of people.

\begin{tabular}{|l|c|c|c|c|c|c|}
\hline \multicolumn{1}{|c|}{ Level of service } & A & B & C & D & E & F \\
\hline Average area occupancy & $>1.21$ & 1.21 & 0.93 & 0.65 & 0.28 & $<0.19$ \\
( sq. m. / person ) & & 0.93 & 0.65 & 0.28 & 0.19 & \\
\hline Density & $<0.83$ & 0.83 & 1.08 & 1.54 & 3.58 & $>5.38$ \\
( person / sq. m ) & & 1.08 & 1.54 & 3.58 & 5.38 & \\
\hline Inter.-person spacing & $>1.22$ & 1.22 & 1.07 & 0.91 & $<0.61$ & Contact \\
( m ) & & 1.07 & 0.91 & 0.61 & & \\
\hline
\end{tabular}

Table 2. "Occupation/queuing".

\begin{tabular}{|l|c|c|c|c|c|c|}
\hline \multicolumn{1}{|c|}{ Level of service } & A & B & C & D & E & F \\
\hline Average area occupancy & $<0.30$ & 0.30 & 0.43 & 0.71 & 1.07 & $>2.15$ \\
(sq. m / person) & & 0.43 & 0.71 & 1.07 & 2.15 & \\
\hline Sped & $>79.25$ & 79.25 & 76.20 & 70.17 & 60.96 & $<33.53$ \\
(m / min.) & & 76.20 & 70.10 & 60.96 & 33.53 & \\
\hline Specific flow & $<22.97$ & 22.97 & 32.81 & 49.21 & 65.62 & $>82.02$ \\
(Pers./m min.) & & 32.81 & 49.21 & 65.62 & 82.02 & \\
\hline
\end{tabular}

Table 3. "Walkway". 


\begin{tabular}{|l|c|c|c|c|c|c|}
\hline \multicolumn{1}{|c|}{ Level of service } & A & B & C & D & E & F \\
\hline Average area occupancy & $<0.53$ & 0.53 & 0.71 & 1.07 & 1.53 & $>2.69$ \\
( sq. m / person ) & & 0.71 & 1.07 & 1.53 & 2.69 & \\
\hline Speed & $>38.01$ & 38.01 & 36.58 & 35.05 & 32.00 & $<25.91$ \\
( m / min.) & & 36.58 & 35.05 & 32.00 & 25.91 & \\
\hline Specific flow & $<16.40$ & 16.40 & 22.97 & 32.81 & 42.65 & $>55.77$ \\
(Pers./ m min.) & & 22.97 & 32.81 & 42.65 & 55.77 & \\
\hline
\end{tabular}

Table 4. "Descending stairway".

\section{References}

Berlin, G. N., (1980). A network analysis of building egress system. ORSA/TIMS meeting Washington.

Brown, J. R. (1979). The knapsack sharing problem. Operation Research, 27(2), 340-355.

Choi, W., Hamacher, S., \& Tufekci, S. (1988). Modelling of building evacuation problems by network flows with side constraints. European Journal of Operational Research, 35, 98-110.

Francis, R. L. (1979). A simple graphical procedure to estimate the minimum time to evacuate a building. Society of Fire Protection Engineers, Technology Report 1979-5, $14 \mathrm{p}$.

Francis, R. L. (1981). A 'Uniformity principle' for evacuation route allocation. J ournal of Research of National Bureau of Standards, 86, 509-513.

Francis, R. L., Chalmet, L. G., \& Saunders, P. B. (1982). Network models for building evacuation. Management Science, 28, 86-105.

Francis, R. L., \& Kisko, T. M. (1984). Network models of building evacuation: Development of software system. Grant No. NB81NADA2057, 62 p.

Francis, R. L., \& Kisko, T. M. (1985). EVACNET+: A Computer program to determine Optimal building evacuation plans. Fire Safety J ournal, 9, 211-220.

Fruins, J. J. (1971-1987). Pedestrian planning and design. Library of Congress Catalogue Number 70-159312: Elevator World.

Galea, E. R., \& Galparsoro, J. M. P. (1993). Exodus: An evacuation model Mass Transport Vehicles. London: UK CAA paper 93006. 
Galea, E. R., \& Galparsoro, J. M .P. (1994). A computer based simulation model for the prediction of evacuation from mass transport vehicles. Fire Safety J ournal, 22, 341-366.

Galea, E. R., Gwinne, S., Lawrence, P., \& Filipidis, L. (2001). Modeling occupant interaction with fire conditions using the building EXODUS evacuation model. Fire Safety J ournal, 36(4), 327-357.

Getachew, T. (1992). An algorithm for multiple-objective path optimization with time dependent links. Paper presented at the 10th International conference on multi-criteria decision making.

Getachew, T., Kostreva M., \& Lancaster L. (2000). A Generalization of Dynamic Programming for Pareto Optimization in Dynamic Networks. RAIRO Operation Research, 34, 27-47.

Gupta, A. K., \& Yadav, P. K. (2004). SAFE-R: a new model to study the evacuation profile of a building. Fire Safety Journal, 39, 539-556.

Hope, B., \& Tardos, E. (1994). Polynomial time algorithms for some evacuations problems, Paper presented at the Fifth Annual SIAM Symposium on Discrete Algorithms.

Hope, B., \& Tardos, E. (1995). The Quickest Transshipment Problem. Paper presented at the 6th Annual SIAM Symposium on Discrete Algorithms.

Kholshenikov, V. V., Shields, T. H., Boyce, K. E., \& Samoshin, D. A. (2006). Recent developments in pedestrian flow theory and Research in Russia. Fire Safety Journal, 43, 108-118.

Kostreva, M. M., \& Getachew, T. (1991). Optimization models in fire egress analysis for residential buildings Paper presented at the Third International Symposium (Elsevier Applied Science).

Lin, P., Lo, S. M., Huang, H. C., \& Yuen, K. K. (2008). On the use of multi stage time-varying quickest time approach for optimization of evacuation planning (Department of Building \& Construction, City University of Hong Kong, Hong Kong). Fire Safety J ournal, 43, 282-290. 
Lo, S. M., \& Fang, Z. (2000). A Spatial-Grid Evacuation Model for Buildings. J ournal of Fire Science, 18, 376-394.

Lo, S. M., Huang, H. C., Wang, P., \& Yuen, K. K. (2006). A game theory based exit selection model for evacuation (8Fire Safety and Disaster Prevention Group, Department of Building \& Construction, City University of Hong Kong, Hong Kong). Fire Safety J ournal, 41, 364-369.

London Transport Board (1958). Second Report of the Operational Research Team on the Capacity of Footways. London: London Transport Board.

Lovas, G. G., Wiklund, J., \& Drager,H. (1992). Evacuation models and objectives. Paper presented at the 1992 Emergency Management and Engineering Conference: Managing Risk with Computer Simulation. Society for Computer Simulation.

Lovas, G. G. (1995). On performance measures for evacuation systems. European J ournal of Operational Research, 85, 352-367.

Lovas, G. G. (1998). Models of way finding in emergency evacuations. European J ournal of Operational Research, 105, 371-389.

Lu, Q., Huang, Y., \& Shekhar, S. (2003). Evacuation Planning: A Capacity Constrained Routing Approach. Department of Computer Science and Engineering (University of Minnesota, Minneapolis, USA), 111-125.

Lu, Q., Huamng, Y., \& Shekhar, S. (2003). Evacuation Planning: A Capacity Constrained Routing Approach. Department of Computer Science and Engineering (University of Minnesota, Minneapolis, USA), $11 \mathrm{p}$.

Lu, Q., George, B., \& Shekhar, S. (2005). Capacity Constrained Routing Algorithms for Evacuation Planning: A Summary of Results. Working paper, 291-307

Megiddo, N. (1974). Optimal Flow in Networks with Multiple Sources and Sinks. Mathematical Programming, 7, 97-107.

Megiddo, N. (1979). Combinatorial Optimization with Rational Objective Functions. Mathematics and Operation Research, 4, 414-424. 
Melinek, S. J., \& Booth, S. (1975). An analysis of evacuation times and movement of crowds in buildings. Building Research Establishment, CP 96/75.

Minieka, J. L. (1973). Maximal, Lexicographic and Dynamic Network Flows. Operation Research, 12(2), 517-527.

Nelson, H. E., \& McLennan, H. A. (1996). Emergency Movement. In The SFPE Handbook of Fire Protection Engineering. Section 3/Chapter 14 (pp. 3.286-3.295). Natl Fire Protection Assn.

Pauls, J. L., \& Jones B. K. (1980). Building Evacuation: Research Methods and case Studies. Fires and Human Behavior, 227-251.

Pauls, J. L. (1984). The movement of people in buildings and design solutions for means of egress. Fire Technology, 20(1), 27-.

Pauls, J. L. (1996). Movement of people. In The SFPE Handbook of Fire Protection Engineering, Section 3/Chapter 12 (3-263/3-285). Natl Fire Protection Assn.

Predtechenskii, W. M., \& Milinskii, A. I. (1969-1978). Planning for foot traffic flow in buildings, Amerind Publishing Co. New Delhi, National Bureau of Standards, U.S. Dep. Commerce, PB-294 993-T, 238 p.

Resier, M. (1978). Mean Value Analysis of Queuing Network Models: A new look at an old problem. Yorktown: IBM Research Report.

Resier, M., \& Lavenberg, S. (1980). Mean Value Analysis of Queuing Network Models. JACM, 27, 313-322

Smith, J. M., \& Karbowicz, C. J. (1984). A K-shortest paths routing heuristic for stochastic network evacuation models. Engineering Optimization, 7, 253-280.

Smith, J. M., \& Talebi, K. (1985). Stochastic network evacuation models. Computers \& Operations Research, 12(6), 559-577.

Smith, J. M., \& Bakuli, D. (1996). Resource allocation in state dependent emergency evacuation networks. European Journal of Operation Research, 89, 543-555. 
Togawa, K. (1955). Study of fire escape based on the observation multitude currents. Japan Building Research Institute, Report 55-14.

Thompson, P. A., \& Marchant, E. W. (1995). A computer model for the evacuation of large building populations. Fire Safety J ournal, 24, 131-148.

Thompson, P. A., \& Marchant, E. W. (1995). Testing and application of the computer model SIMULEX. Fire Safety J ournal, 24, 149-166.

Tjandra, A. S. (2004). Earliest Arrival Flow with Time Dependent Capacity Approach to the Evacuation Problems. Working paper, 24 p.

Tjandra, A. S. (2003). Dynamic Network Optimization with Application to the Evacuation Problems. PhD thesis at the Technische Universität Kaiserslautern, Kaiserslautern, Germany.

Weinroth, J. (1989). An adaptable microcomputer model for evacuation management. Fire Technology, 291-307.

Wiecek, M. (1992). Multicriteria decision making in fire egress analysis. Workshop at the IFAC/IFORS. Workshop on Support Systems for Decision and Negotiation.

Wiecek, T. (1993). Time dependency in multiple-objective dynamic programming. J ournal of Mathematical Analysis and Applications, 173, 289-307.

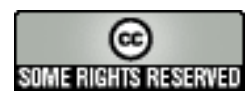

Article's contents are provided on a Attribution-Non Commercial 3.0 Creative commons license. Readers are allowed to copy, distribute and communicate article's contents, provided the author's and Journal of Industrial Engineering and Management's names are included. It must not be used for commercial purposes. To see the complete license contents, please visit http://creativecommons.org/licenses/by-nc/3.0/. 